\title{
Study of the Nonlinear Relationship between R\&D Investment and Regional Innovation Capacity: Evidence from Panel Threshold Model
}

\author{
Kai Sun ${ }^{*}$ and Yanchun Liu \\ Business School of Liaoning University, Liaoning Shenyang 110036, China \\ ${ }^{*}$ Corresponding author
}

\begin{abstract}
Choosing panel data of 30 provinces (except Tibet, Hong Kong, Macao and Taiwan) within years of 2007-2015 as research samples in China, and use the financial development level as threshold variable. By using the panel threshold model we investigate the nonlinear relationship between $R \& D$ investment and regional innovation capacity. The results show that $R \& D$ investment and regional innovation capacity have significant "single threshold effect" based on the threshold variable. The nonlinear relationship between $R \& D$ investment and regional innovation capacity in China is significant. $R \& D$ labor investment has a significant positive effect on regional innovation capacity. The factors that promoting the regional innovation capacity are $R \& D$ labor investment, urbanization level, the government investment. The level of the industrial structure and financial development level impact on China's regional innovation capacity is not significant. When the financial level is in different interval, there is a significant different influence between $R \& D$ investment and regional innovation capacity.
\end{abstract}

Keywords- $R \& D$ investment; regional innovation capacity; panel threshold model

\section{INTRODUCTION}

\section{A. Regional Innovation in China}

With the advent of the global economy and information age the differences in regional economic development are gradually increasing. More and more research and practice show that regional innovation capability plays an increasingly important role in regional economic development. In the process of regional economic development, we know that the land, capital and other factors have the effect of diminishing marginal revenue. It has become increasingly unsuitable for the strategic requirements of sustainable development to rely entirely on the traditional and extensive growth mode of economic development with the features of cheap labor, high investment, high savings. In order to promote the rapid development of regional economy and reduce the diminishing rate of marginal revenue of elements including capital, it is necessary to integrate innovation into the elements of investment to promote the driving force of economic development through the implementation of the new combination of factors, improving the total factor productivity of elements. It can be seen that regional innovation capability is the internal driving force of the regional economic development and the difference of regional innovation capability is the source of regional economic development.

\section{B. Related Literature}

The $18^{\text {th }}$ Party Congress put forward the innovation-driven strategy. Recently, the CPC Central Committee and the State Council have issued the Outline of the National InnovationDriven Development Strategy, putting innovation at the core of the overall development of the country. That the importance of regional innovation capability and the attention of the country has aroused extensive consideration in academia. Some scholars have studied the impact of R\&D investment on regional innovation capacity. Most scholars believe that there is linear relationship between $R \& D$ investment including $R \& D$ labor, R\&D capital and regional innovation. Tongyao Shao and Yan Pan (2011) ${ }^{[1]}$ propose that the VC, R\&D investment have positive influence on the regional innovation output through the panel data of 27 provinces in China from 2006 to 2008 . Zhengying Luo and Yanjie Xu (2014) ${ }^{[2]}$ analyzes the regional innovation capability of Jiangsu Province in the view of R\&D investment. Wu Zhao (2015) ${ }^{[3]}$ suggests that R\&D investment and $\mathrm{VC}$ play a positive role in promoting the output of innovation based on the linear and PLS regression using the data of $\mathrm{VC}$, science and technology investment and innovation output from 1994 to 2012. Some scholars have tried to introduce $R \& D$ variable into a non-linear form of research. Xinqiao Chen and Pinliang Luo(2005) ${ }^{[4]}$ exams the non-linear power function relationship between the innovation input such as human factors, capital factors and innovation output. On the basis of combing the transmission mechanism of R\&D investment in the influence of FDI on the innovation capability of the host country, Jun Luo and Jianguo Chen (2014) ${ }^{[5]}$ test the threshold effect of R\&D capital investment and R\&D labor investment on China's regional innovation capability based on panel threshold model using the provincial panel data of China from 2002 to 2012 . Yonghua $\operatorname{Wang}(2015)^{[6]}$ notes that the impact of human capital on regional innovation capability is not linear according to the existence of double threshold effect based on the threshold variable telecommunication infrastructure between human capital and regional innovation capability by taking the panel data of 28 provinces in China from 1993 to 2012. Most scholars argue that the R\&D investment has a significant positive impact on innovation capacity, and some scholars believe that the positive impact is not significant. Pei Shi and Yongjian $\mathrm{Pu}(2011)^{[7]}$ propose that 
material capital has a significant positive impact on regional innovation capacity, but the influence from human capital and knowledge mobility capacity to regional innovation ability is not obvious. Shuaibing Zhang(2013 $)^{[8]}$ has the idea that intensity of R\&D personnel has negative correlation to the new application of patent per person and technical assets by taking 65 listed information technology companies as a sample. Innovative activities have the characteristics of public goods. The government can provide some support for enterprise innovation activities through tax incentives or guidance funds, etc. Some scholars have studied the impact of government behavior on regional innovation capacity. Xiaofei $\mathrm{Wu}(2016)^{[9]}$ finds that there is a kind of obvious inverted U-type relationship between local government's science and technology subsidy and regional innovation through the fixed effect model by taking the data of provinces in China from 1998 to 2013 as a research sample. On the basis of stochastic frontier model of transcendental logarithm and the threshold regression model, Ping Li and Lili Liu(2017) ${ }^{[10]}$ argue that the impact of government R\&D funding on innovation efficiency is negative and there is a certain "government failure" by taking panel data of provinces in China from 2003 to 2012. What the level of regional financial development is reflected in whether it can mobilize the necessary fund for innovative activities at the high speed and with low cost. It can effectively reduce financial cost and improve the success possibility of innovative activities with a variety of financial product innovation and diversified supply channels. Some scholars have studied the impact of financial factors on regional innovation capacity. Jian $\mathrm{Li}$ and Ping Wei (2016) ${ }^{[11]}$ argue that the financial scale and efficiency have a significant effect on regional innovation ability based on the dynamic panel model by using the provincial balance panel data from 2000 to 2012 .

\section{About this Study}

Through the existing literature, we can find that the vast majority of scholars believe that there is a linear relationship among R\&D investment, government factors, financial factors and regional innovation capacity. In this paper, taking the panel data of 30 provinces in China from 2007-2015 as research sample, choosing financial development level as threshold variable, we study the nonlinear relationship between $R \& D$ investment and regional innovation capacity based on the panel threshold model, then proposing relevant policy suggestions according to the research results.

\section{THE SELECTION AND THE DESCRIPTION OF THE DATA}

\section{A. The Selection of Variables}

Based on the principle of data availability, this paper chooses the panel data of 30 provinces (except Tibet, Hong Kong, Macao and Taiwan) in China from 2007 to 2015 as the research samples. The data such as the number of patent applications per million, the ratio of the second industry product to gross domestic product, the ratio of urban population to resident population, the expenditure on science and technology in the general budget expenditure, the resident RMB savings deposit per capita at the end of the year comes from the 2008-2016 China Statistic Yearbook. The data such as the regional $\mathrm{R} \& \mathrm{D}$ staff all-time equivalent, the regional $\mathrm{R} \& \mathrm{D}$ expenditure comes from 2008-2016 "China Statistic Yearbook of Science and Technology". The econometric software in this paper is Stata 12.0.

1) Dependent variable: For the measurement of regional innovation capacity, different scholars will choose different indicators. The use of indicators are usually the number of patent applications, the number of patent licenses, the number of scientific papers published and so on. The independent variable in this paper is regional innovation capacity which is reflected by the number of patents licenses (INNO).

2) Key independent variables: We choose $R \& D$ labor investment (RDL) and R\&D capital input (RDK) as the key independent variables. Using regional $R \& D$ staff all-time equivalent to reflect $\mathrm{RDL}$, regional $\mathrm{R} \& \mathrm{D}$ capital stock to reflect RDK. This paper uses the perpetual inventory method to estimate the RDK which is as follows.

$$
R D K_{i t}=(1-\eta) R D K_{i, t-1}+I_{i t} / P_{i t}
$$

RDK represents $R \& D$ capital stock. I is for current expenses. I stands for province and $t$ is for time. $\eta$ represents depreciation rate. $P$ stands for $R \& D$ price index. In the conversion, how to set the R\&D price index has been the difficulty of economics. This paper draws on relevant references, constructs that

$$
R \& D \text { Price Index }=\beta_{1} \times \text { Fixed Aseet Price Index }+\beta_{2} \times C P I
$$

Convert the fixed asset price index (FAPI) and CPI into constant price based on the 2006 price index. Parameter select $\beta_{1}=0.45, \beta_{2}=0.55$. Finally, according to the R\&D price index on the R\&D capital to reduce, resulting in R\&D capital stock. For how to set the R\&D capital stock in 2006, reference to approach of scholars, that is

$$
R D K_{i 0}=I_{i 0} /\left(\eta+g_{i}\right)
$$

$\mathrm{RDK}_{\mathrm{i} 0}$ indicates the $\mathrm{R} \& \mathrm{D}$ capital stock in $2006 . \mathrm{I}_{\mathrm{i} 0}$ is the R\&D capital after the reduction. $g$ stands for the average annual growth rate of R\&D capital for each region from 2006 to $2015 . \eta$ is for the depreciation rate of R\&D capital stock with reference to some scholars set value, here take $10 \%$. Combining with the two formulas, we can get the R\&D capital stock of 30 provinces in China from 2006 to 2015.

3) Threshold variables: We choose financial development level as the threshold variable. Using the resident RMB saving deposit per capita at the end of the year to reflect FIN.

4) Control variables: The influencing factors of regional innovation capacity are complex and diverse. In order to avoid the endogenous problems, we choose the industrial structure level (INS), urbanization level (URB) government investment (GOV) as the main control variables. The INS is reflected by the ratio of the second industry product to gross domestic product. URB is reflected by the ratio of urban population to 
resident population. Using expenditure in science and technology of general budget to reflect the GOV,

\section{B. The Description of the Variables}

In order to reduce the time series error and heteroscedasticity that may occur between different, the INNO, RDL, RDK, GOV, FIN are logarithmized in the process of dealing with data. As the INS, URB are the ratio data, we do not perform logarithmic processing to avoid the negative. Related description statistics are as following table.

\section{TABLE I. THE STATISTICAL CHARACTER OF EACH VARIABLE}

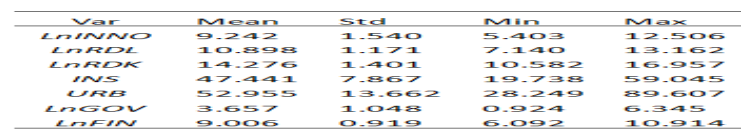

\section{THE CONSTRUCTION OF THE MODEL}

Based on traditional Cobb-Douglas production function we construct the new knowledge production function model which can reflect the regional innovation capacity because the R\&D investment and regional innovation capacity are input-output relationship.

$$
I N N O_{i t}=R D L_{i t}^{\alpha} R D K_{i t}^{\beta}
$$

INNO is for the output of knowledge, RDL, RDK are respectively on behalf of the $R \& D$ labor investment, $R \& D$ capital investment. $\alpha$ and $\beta$ are respectively on behalf of the flexibility of RDL and RDK. I stands for province and $t$ is for time in (1).

On both sides of (1), take $t$ logarithm and introduce the control variables and threshold variables. We can get the following (2).

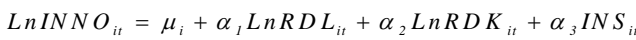

$$
\begin{aligned}
& +\alpha_{4} U R B_{i t}+L n G O V_{i t}+L n F I N_{i t}+\varepsilon_{i t}
\end{aligned}
$$

It does not consider the threshold effect in (2). Financial level will also have an impact on corporate $R \& D$ investment which will lead to the changes of regional innovation capacity and these changes may also be non-linear. To refer to the Hansen (1999) ${ }^{[12]}$ threshold regression model approach, choose the logarithm of financial development level(FIN) as the threshold variables, on the basis of (2) we construct single threshold model (3), (4), when we suppose that there is single threshold effect first.

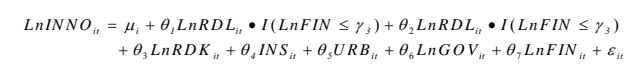

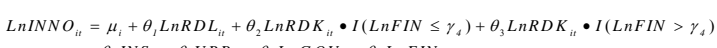$$
+\theta_{4} I N S_{i t}+\theta_{5} U R B_{i t}+\theta_{6} L n G O V_{i t}+\theta_{7} \operatorname{LnFIN}_{i t}+\varepsilon_{\text {it }}
$$

parentheses is true, it will equal 1 otherwise the value will be zero. $\Upsilon$ stands for the threshold value. $\mu$ is for the individual intercept term, indicating that this is a fixed effect model. Obviously this is a non-linear regression because it can't be written as a linear function of the parameter form.

\section{THE ANALYSIS OF THE EMPIRICAL RESUlTS}

\section{A. Common Panel Model Analysis}

For the empirical analysis of ordinary panel, we can consider using the methods of mixed OLS, fixed effect panel model and random effect model. Which method we need to choose should be based on the features of the sample. The Hausman test is performed on the sample data, we reject the null hypothesis which is using the random effect model because the Hausman statistic value is 63.11 . So we choose the alternative hypothesis which is fixed effect model and the results are shown in the table

\section{TABLE II. THE RESULT OF THE PANEL FIXED EFFECT MODEL}

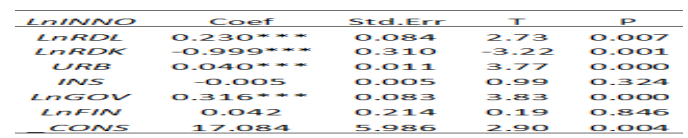

Table 2 shows that the influence of R\&D labor investment on innovation capacity is significant at the $1 \%$ level. The level of industrial structure has negative impact on the regional innovation capacity, but it's not significant. The financial development level has a positive impact on China's regional innovation, but it does not pass the significance test at the $10 \%$ level. Urbanization level and government investment have a significant positive impact on China's regional innovation capacity at the $10 \%$ level.

\section{B. Analysis of the Panel Threshold Model}

1) The test of the threshold effect: Choosing the financial development level as the threshold variables to test the threshold effect. In order to use a single threshold, double threshold and triple threshold hypothesis to do the bootstrap test to determine the number of the threshold value. To determine the threshold model according to the test of the F statistic and $\mathrm{P}$ value. Table 3 shows that the single threshold effect, the double threshold are significant at the $1 \%$ level and the triple threshold effect is significant at $5 \%$ level when the financial development level as the threshold variable and respectively the $R \& D$ labor investment, $R \& D$ capital stock as the key independent variables. At the same time, we find that if we use the double threshold model, the $95 \%$ conf. interval will contain the single threshold value and if the triple threshold model was used, the $95 \%$ conf. interval will contain the second threshold value. Therefore, we should choose the single model to test the threshold effect that the financial level impact on the regional innovation capacity.

LnFIN is for the threshold variable and the key variables are respectively LnRDL and LnRDK in (3) and (4). I (g) is a kind of explicit function, that is, if the expression in 
TABLE III. THE TEST OF THRESHOLD EFFECT

\begin{tabular}{|c|c|c|c|c|c|c|c|c|}
\hline var & Keyvar & Model & F-stat & P-value & BS & & critical & \\
\hline EnFIN & $\angle A F D C$ & $\begin{array}{l}\text { Single } \\
\text { Double } \\
\text { Trible }\end{array}$ & $\begin{array}{l}29.419^{4+1} \\
21.505^{*+1} \\
10950^{* 2}\end{array}$ & $\begin{array}{l}\text { o.ono } \\
\text { o.ooo } \\
0.030\end{array}$ & $\begin{array}{l}300 \\
300 \\
300\end{array}$ & $\begin{array}{l}14.641 \\
21.5960 \\
17686\end{array}$ & $\begin{array}{l}8.642 \\
11.883 \\
8.267\end{array}$ & $\begin{array}{l}5.831 \\
7.454 \\
6280\end{array}$ \\
\hline LMFIN & $\angle M R D K$ & $\begin{array}{l}\text { Sinele } \\
\text { Double }\end{array}$ & $\begin{array}{l}29.176^{*} * * \\
22.594 *\end{array}$ & $\begin{array}{l}\text {.0.000 } \\
\text { o.013 } \\
0.013\end{array}$ & $\begin{array}{l}300 \\
300 \\
300\end{array}$ & $\begin{array}{l}13.797 \\
27.032\end{array}$ & $\begin{array}{l}6.792 \\
11.592\end{array}$ & $\begin{array}{l}5.402 \\
8.219\end{array}$ \\
\hline
\end{tabular}

After the threshold effect test, the threshold value needs to be estimated and tested. Table 4 shows the threshold value of triple threshold model and 95\% conf. interval. Fig 1 shows the likelihood relation diagram of the single threshold model when the financial level as the threshold variable and R\&D labor investment as the key independent variable. The dotted line indicates the critical value of the likelihood ratio statistic. The statistic critical is 7.35 according to the formula $c(\alpha)=-2 \operatorname{Ln}(1-\sqrt{1-\alpha})$ proposed by Hansen(1999) when $\alpha$ equal $5 \%$.

TABLE IV. THRESHOLD VALUE AND 95\% CONF. INTERVAL

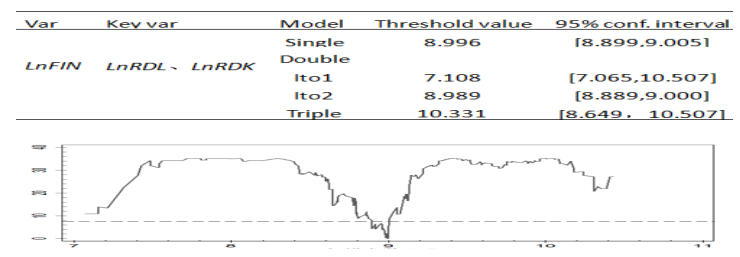

FIGURE I. THE FIRST THRESHOLD VALUE

2) Result analysis of panel threshold model: Table 5,6 show the threshold model estimation results. According to the results in the table we can draw the following conclusions.

a) Table 5 shows that the single threshold value which is 8.996 can divide our sample into two parts. There is a significant difference in the degree of impact of R\&D labor investment on regional innovation capacity at different levels of financial development. The coefficient of LnRDL is 0.264 when the financial development level below the threshold which is 8.996 . The coefficient is 0.284 when the financial development level crosses the threshold value, which has been a certain degree of recovery. It can be seen that with the improvement of financial development level, the positive impact of R\&D labor investment on regional innovation capacity is incresing. From the regression results of other variables, the impact of $R \& D$ capital stock on regional innovation capacity is significantly negative at the $5 \%$ level and the coefficient is -0.723 . The reason for this result may be that the impact of R\&D capital stock on regional innovation capacity has the threshold effect of financial development level.

b) Table 6 shows that the impact of R\&D capital stock does exist the threshold effect of the financial development level. The coefficient of LnRDK is -0.763 when the financial development level below the threshold which is 8.996. The coefficient is -0.747 when the financial development level crosses the threshold value. With the improvement of financial development level, the inhibition is gradually weakened.

c) The results of Table 5 and Table 6 both show that the impact of URB on regional innovation capacity is significant positive at $1 \%$ level, with coefficient of $0.033,0.034$. The impact of INS on regional innovation capacity is negative, but none of them have passed the significanct test. The impact of
LnFIN on regional innovation capacity is positive, but neither has passed the significant test. The impact of LnGOV on regional innovation capacity is significantly positive at the $1 \%$ level.

TABLE V. THE RESULTS OF PANEL THRESHOLD MODEL (3)

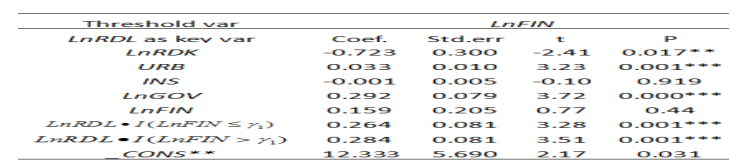

TABLE VI. THE RESULTS OF PANEL THRESHOLD MODEL (4)

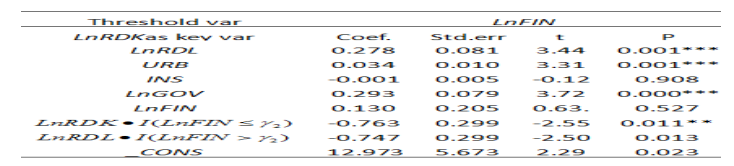

\section{CONCLUSIONS AND POLICY IMPLICATIONS}

\section{A. Conclusions}

In this paper, we discuss the non-linear relationship between R\&D investment and regional innovation capacity by using the panel data of 30 provinces in China from 2007-2015, taking financial development level as the threshold variable. We draw the conclusion as follows.1)There is single threshold effect that the R\&D investment impacts on China's regional innovation capacity on the basis of the threshold variable which is financial development level.2)The non-linear relationship significantly exists between $R \& D$ investment and regional innovation capacity.3) R\&D labor investment has a significant positive effect on China's regional innovation capacity, but the effect of the R\&D capital stock is negative.4)The main factors of promoting regional innovation capacity are $R \& D$ labor, urbanization level, government investment.5)The level of industrial structure and financial development level have no significant effect on regional innovation capacity.6)There are significant differences in the impact of $R \& D$ investment on regional innovation capacity when the financial development level is in different intervals.

\section{B. Policy Implications}

The following suggestions can be put forward for the conclusions of this paper.1)Speed up the reform of the financial system and promote the full liberalization of financial markets. 2)Increase the intensity of government investment and guide business activities oriented.3)Increase R\&D investment and improve the efficiency. 4)Adjust the industrial structure and create new advantages of development.

\section{REFERENCES}

[1] Tongyao Shao,Yan Pan.Venture Capital, R\&D innovation -based on provincial panel of trademark[J]. Science Research,2011,(05):793-800.

[2] Zhengying Luo, Yanjie Xu.Jiangsu regional innovation capacity enhance the effectiveness - based on $\mathrm{R} \& \mathrm{D}$ investment perspective[J].China Statistics,2014,(04):51-52.

[3] Wu Zhao,Xiaohua Li,Mingxuan Zhu.Venture Capital,R\&D Investment on the Impact of Technological Innovation Output Difference[J],Science and Technology Management Research,2015(7):1-5. 
[4] Xinqiao Chen,Pinliang Luo.Enterprise Investment-output Relationship and Its Empirical Study - based on the Analysis of Perfect Competition Market Structure[J].Industry Economics Research,2005,(05):58-63

[5] Jun Luo, Jianguo Chen.R\&D Investment Threshold,FDI and China's Innovation Capacity — based on the Test of Threshold Effect[J].

[6] International trade issues,2014,(08):135-146.

[7] Yonghua Wang.Research on the Nonlinear Relationship between Human Capital and Regional Innovation Capacity - Empirical Evidence based on Panel Threshold Model[J].Economic Issues,2015,(06):47-50.

[8] Pei Shi, Yongjian Pu.Spatial Econometrics Study of Regional Innovation Capacity in China[J].Science and Technology,2011,24 (4):11-15.

[9] Shuaibing Zhang.R\&D Investment,Technology Innovation Output and Profitability[D].Shandong University.2013

[10] Xiaofei Wu. Science and Technology Support,Subsidy Trap and regional innovation capacity[J].Finance and Trade Rearch,2016, (05):99-106.

[11] Ping Li, Lili Liu.Government R\&D Funding,Corporate R\&D Investment and Innovation Efficiency in China[J].Scientific Research Management,2017,V38(1):21-29.

[12] Jian Li, Ping Wei.The Role of Finance in the Promotion of Regional Innovation Capacity - based on the Analysis of China's Provincial Panel Data[J].Urban Problems,2016,(07):55-63.

[13] Hansen B E. Threshold effects in non-dynamic panels: Estimation, testing, and inference[J]. Journal of econometrics, 1999, 93(2): 345-368. 